\title{
EFFECT OF THE PHYSICAL ACTIVITY OF PRESCHOOL CHILDREN ON THE STRENGTH ENDURANCE OF ABDOMINAL, TRUNK AND GLUTEAL MUSCLES
}

\author{
V. Pavlova, R. Paskaleva, V. Ivanova \\ Department of Medical Rehabilitation and Ergotherapy, Physical Medicine and Sport, \\ Faculty of Medicine, Trakia University, Stara Zagora, Bulgaria
}

\begin{abstract}
PURPOSE. The objective of this study is to investigate the static strength endurance of abdominal, trunk and gluteal muscles both in physically active and physically inactive overweight children. MATERIAL AND METHODS. The object of study are 104 children aged 5-6 years in the period 2017-2018 on the territory of the town of Stara Zagora. To investigate the motor activity of children the survey method was used. To determine efficiency of trunk, abdominal and gluteal muscles modified Kraus-Weber test was used according to V. Zhelev, L. Venova. RESULTS. Weaker abdominal and trunk muscles were found in physically inactive children with no statistically significant differences $(\mathrm{P}>0.05)$ between physically active and physically inactive ones. However, the results show the presence of statistically significant differences $(\mathrm{P}=0.01)$ of the mean values for the static strength endurance of gluteal muscles in physically active children 13,9 $9 \pm 8,6 \mathrm{sec}$. and physically inactive children $10,3 \pm 9,4$ sec. with the latter having weaker gluteal muscles, respectively. CONCLUSIONS. Further studies are needed to establish the relationship between the increased body mass of children and the strength endurance of abdominal, trunk and gluteal muscles of physically active and physically inactive children as an indicator counteracting total muscle hypotonia.
\end{abstract}

Key words: overweight, childhood obesity, childhood.

\section{INTRODUCTION}

Preschool age is a period of intense physical and mental development marking the start of personality buildup (1). Early childhood is a key period in which children form patterns of healthy eating and physical activity through personal experience, parents, teachers, and other external factors. According to latest data this is the period when inactive children start being predisposed to negative health consequences at a later age (2). Unfortunately, in recent years there has been significant increase in the number of children with weight exceeding the set range as early as preschool age. According to data by WHO the occurrence of obesity worldwide almost trebled between 1975 and 2016, and in 2016 over 1,9 billion adults above the age of 18 were overweight, of these

\footnotetext{
*Correspondence to: Vanya Pavlova - Stara Zagora, 6000, 11 Armeiska Str., phone number: 0883478788,e-mail:vanya.pavlova@trakia-uni.bg
}

over 650 million were obese (3). According to WHO in 2016 the weight of about 41 million children aged under 5 exceeded the set range. For the age limit between 5 and 19 WHO found over 340 million overweight children and adolescents (3).

A great number of factors play a role in the etiology of obesity and when acting independently and/or in combination they cause increase of weight above the set range $(4,5)$. Along with genetic, endocrine, psychological factors and hypercaloric nutrition, for the excessive increase of the child's body mass hypodynamics in childhood age gains more and more significance. Factors such as reduced motor activity of children in kindergarten and during their free time contribute considerably to hypodynamics. Other conditions for the rise of hypodynamics of children are factors such as the use of personal and public transport instead of 
walking; prolonged stay in front of electronic devices, etc. (6-8).

A number of studies, including in Bulgaria, research the level of motor activity at preschool age. A study by S. Filkova et al. in 2015 in the city of Varna found low level of motor activity among the tested children ( 25 of them) with obesity 1 and 2 grade at the age of 6-14. The results of the study show a significant percentage of physically inactive children during workdays (24\%) and at the weekend $(32 \%)$. It has been established that none of the tested persons copes with the minimum of 120 minutes of sports activities at the weekend (9). A report by Active Healthy Kids Canada revealed that $87 \%$ of children and adolescents do not meet the Canadian instructions for 90 minutes of physical activity daily (10).

The studies by S. Vale et al. (2010) in Portugal (the urban area of Porto) investigated the relationship between physical activity (measured by an accellerometer) and BMI of 281 children aged 4 to 6 . Greater percentage $(43,9 \%)$ of overweight and obese children is noticed with low level of physical activity compared to those with normal weight $-32,1 \%$ (11). M. Lateva et al. (2009) also studied the level of physical activity at preschool age (4-6 years) among 727 overweight and obese children. The authors established significantly lower BMI values in girls with longer daily physical activity (12).

According to the American pediatric association motor activity of children is limited both in duration and intensity, which has adverse effect on their health and weight. The American pediatric association recommends children at preschool age to have structured physical activity at least 60 minutes daily. This includes activities such as football, swimming, ballet, gymnastics, regular walking and playing, exercises for developing the motorics, such as catching a ball, exercises for balance, rope skipping, etc. (Garcia, 2002). It is important they to be involved from 60 minutes to several hours in non-structured physical activity - climbing trees, running, hide-andseek, cycling, playing with a ball in the yard, etc. and static activities (without sleeping time) to be reduced to a maximum of 60 minutes per day (13).

S. Filkova et al. (2015) recommend at least 60 minutes of physical activity every day to maintain the health status of children. According to the authors parents should provide their children with daily walking and playing outdoors for several hours even when the weather is not good. The authors recommend parents to do sports together with their children, which not only improves communication with the child, but has beneficial effect on parents as well (9).

The studied data concerning the growing hypodynamics among children pose the need for increasing the motor activity of the youngest. The benefits of movement and physical exercises on the child's organism have been proven for a long time. According to a number of authors, different types of motor activities activate physical processes and eliminate mental fatigue; the strength and mobility of nervous processes are improved; metabolic processes are activated until complete decomposition and assimilation of the absorbed nutrients without fat deposition; metabolic processes of the organism speed up and its protective abilities increase; valuable moral and volitional physical qualities of the personality are formed (14-18). Favourable changes take place in the musculoskeletal system as well - changes in bone growth and skeletal muscle formation (14, $19,20)$. The activity of the cardiovascular system is improved, with an increase in the stroke volume of the heart and a decrease in the values of the pulse rate and blood pressure. Systemic physical activity results in an increase in the vital capacity of the lungs and pulmonary ventilation. Blood supply to the brain is improved. Mental processes improve, memory and thinking become more sustainable and school performance also improves $(16-18,21)$.

The aim of the present study was to examine the static strength of abdominal, trunk and gluteal muscles in overweight children who are physically inactive and those who are not.

\section{MATERIAL AND METHODS}

Subject of the study are 104 children at 5 to 6 years of age from 25 kindergartens on the territory of Stara Zagora municipality. The survey of the motor activity and incidence of overweight and obesity among children born in 2011 and 2012 was part of a research project of the Faculty of Medicine at Trakia University - Stara Zagora entitled "Prevention and early diagnosis of spinal deformities in kindergartens - innovative element of practical 
training of students from the major Medical Rehabilitation and Ergotherapy in co-operation with Stara Zagora municipality.

A survey method was used to study the motor activity of children. To determine the capacity of the trunk, abdominal and gluteal muscles, a modified Kraus-Weber test was applied according to V. Zhelev, L. Venova (1997). Only three test items from the static part of the test were used in the study to determine the strength of the abdominal, trunk and gluteal muscles. Namely: testing of the abdominal muscles and the flexors of the hip joint without fixation, from starting body position - supine; testing trunk muscle extensors from prone position; testing of lower limb extensors from prone position. The surveyed children had to keep according to their abilities, and the time was recorded in seconds.

\section{RESULTS AND DISCUSSION}

The representative samples of 104 children comprised more girls $(n=61)$ than boys $(n=43)$. Having determined obesity degree according to BMI and the percentile method, it was found out that 22 of the studied children $(21,2 \%)$ were with normal weight, $20(19,2 \%)$ were overweight and $62(59,6 \%)$ were obese. From the surveyed 5-year-old children, abnormally high BMI was found in $18,4 \%$, while $65,3 \%$ were obese. Among the 6-year-old children, overweight was detected in $20 \%$ and obesity in $54,5 \%$. The incidence of overweight children increased with age: from $18,4 \%$ in 5 year-olds to $20 \%$ at 6 years of age. In the obesity group, the reverse tendency was present: decrease from $65,3 \%$ in 5-year-old children to $54,5 \%$ in 6-year-olds. No statistically significant differences with respect to age were found $(\mathrm{P}>0.05)$ (Figure 1).

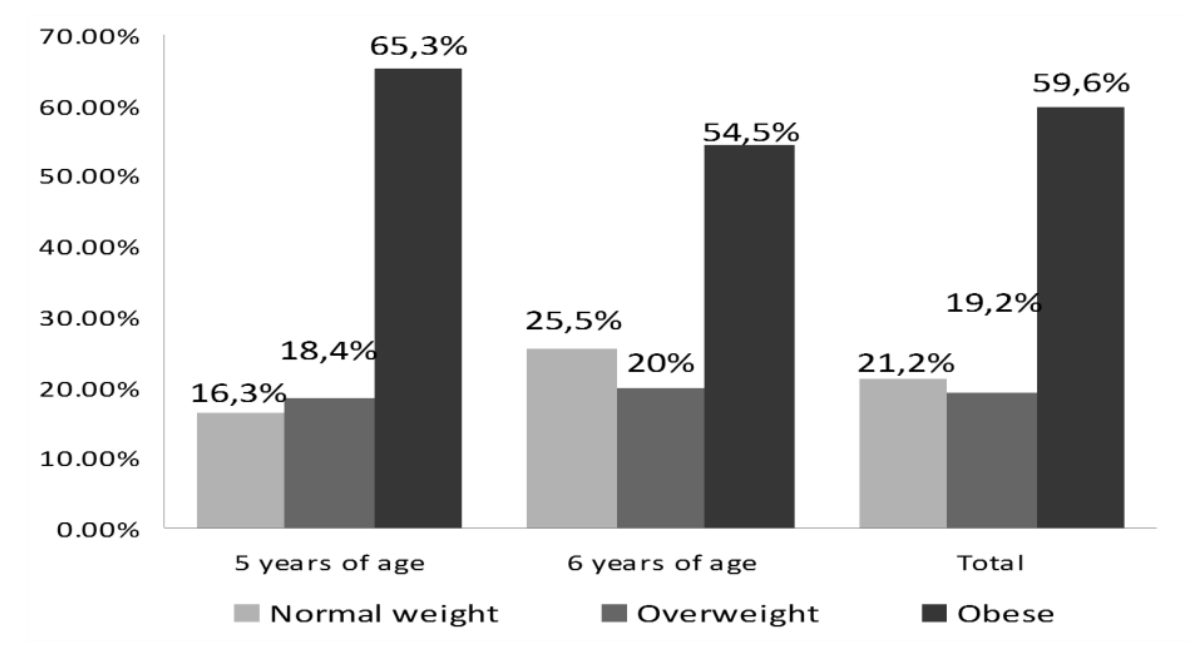

Figure 1. Distribution of BMI groups according to age of children.

It was interesting for us to find out what part of the children are involved in sports activities in their leisure time. A high percentage of the surveyed children were not involved in any sports activity out of the kindergarten $-66,1 \%$ $(n=72)$. Those engaged in some sport in their leisure time were a relatively small group $28,4 \% \quad(n=31)$ and only 5,5\% $(n=6)$ of the children were occasionally engaged in some sport. This could be one of the factors responsible for the low level of physical activity at that age, resulting in overweight. Other causes could be found, in our view, in the lack of habits for physical activity and sport at an early age, lack of appropriate facilities and ready access to them. Figure 2 depicts the proportions of children engaged in sport out of the kindergarten. According to the results, $33,9 \%$ did sport regularly or occasionally, yet the share of those who did not do any sport remained about twice greater.

Comparative analysis of body weight of children and sport activity out of the kindergarten was made. The analysis of results revealed higher proportion of overweight children among those who did not do sport (65\% vs $35 \%$ doing sport. In the group of obese children the results were similar $-66.1 \%$ not involved in sport vs 33,9\% doing sport but the differences were not statistically significant (Table 1 and Figure 3). 
PAVLOVA V., et al.

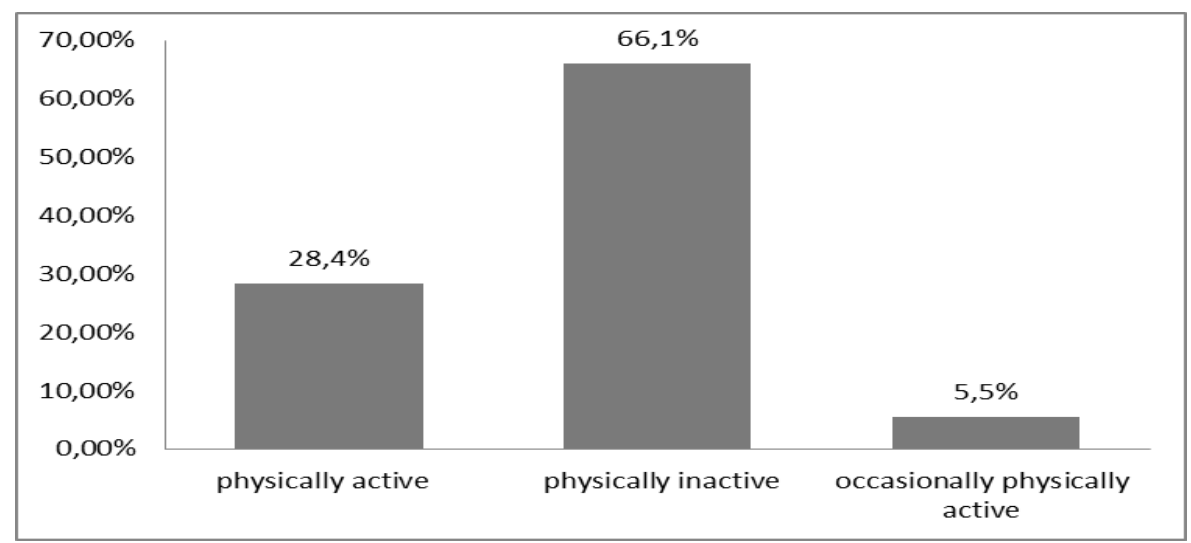

Figure 2. Distribution of children doing sport out of the kindergarten.

Table 1. Distribution of physically active children according to BMI

\begin{tabular}{|c|c|c|c|c|c|}
\hline & \multicolumn{3}{|c|}{ BMI groups } & \multirow[b]{2}{*}{ Total } \\
\hline & & $\begin{array}{l}\text { Normal } \\
\text { weight }\end{array}$ & Overweight & Obesity & \\
\hline \multirow[t]{2}{*}{ Physically active } & number & 7 & 7 & 21 & 35 \\
\hline & \% BMI groups & $31,8 \%$ & $35,0 \%$ & $33,9 \%$ & $33,7 \%$ \\
\hline \multirow{2}{*}{$\begin{array}{l}\text { Physically } \\
\text { inactive }\end{array}$} & number & 15 & 13 & 41 & 69 \\
\hline & \% BMI groups & $68,2 \%$ & $65,0 \%$ & $66,1 \%$ & $66,3 \%$ \\
\hline \multirow[t]{2}{*}{ Total } & number & 22 & 20 & 62 & 104 \\
\hline & \% BMI groups & $100 \%$ & $100 \%$ & $100 \%$ & $100 \%$ \\
\hline
\end{tabular}

The incidence of overweight and obesity in the group of children engaged regularly in sport confirmed that maintenance of normal weight required also a proper diet. The integral approach combining appropriate motor activity and diet is therefore essential for treatment of obesity in children.

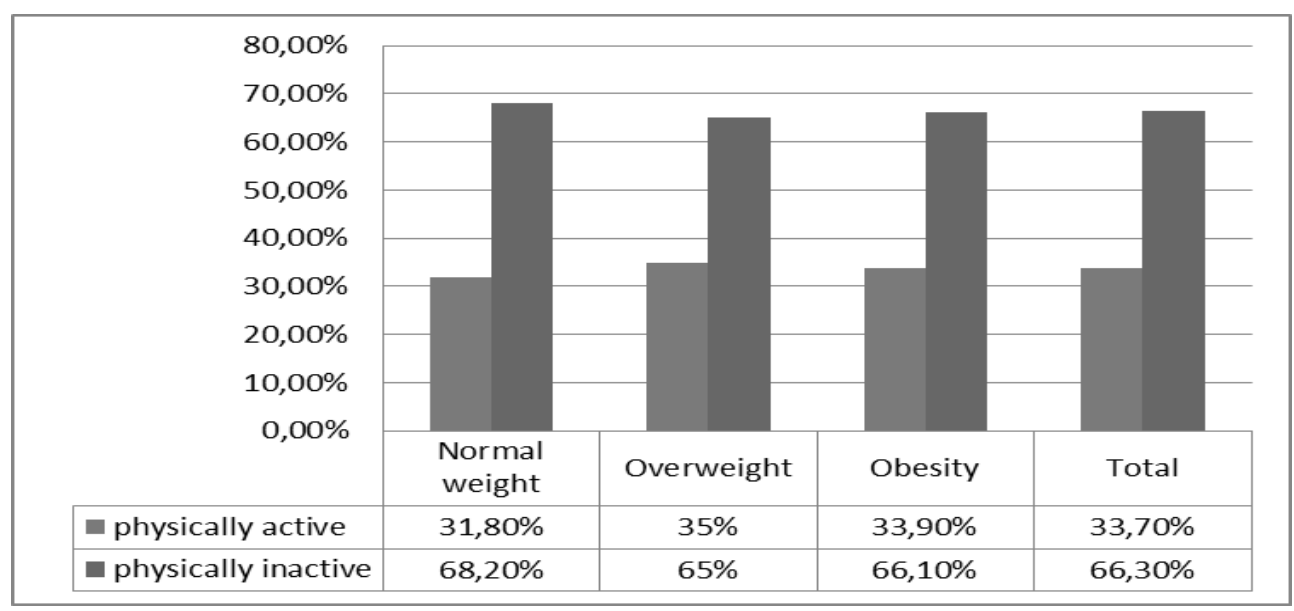

Figure 3. Distribution of BMI groups in physically active and physically inactive children.

Analysis of lower limb, abdominal and trunk muscles strength. The comparison of the mean values from the three muscle groups showed the highest strength for trunk extensors:
$25.9 \pm 16.7 \mathrm{~s}$, followed by abdominal muscles and hip flexors $-14.6 \pm 9.8 \mathrm{~s}$ (mean $\pm \mathrm{SD})$. The strength of lower-limb extensors was the least (11.4 $\pm 9.4 \mathrm{~s})$ (Table 2).

Table 2. Strength of trunk, abdominal and hip muscles

\begin{tabular}{|l|l|l|l|l|l|}
\hline & $\mathrm{N}$ & Minimum & Maximum & Mean & Standard deviation \\
\hline Abdominal and hip flexors & 104 & 0 & 56 & 14.64 & 9.803 \\
\hline Trunk extensors & 104 & 0 & 100 & 25.88 & 16.703 \\
\hline Lower-limb extensors & 104 & 0 & 45 & 11.45 & 9.406 \\
\hline
\end{tabular}


The effect of body weight on the strength of abdominal, trunk and gluteal muscles was also studied. An indirect weak correlation was established between BMI and abdominal flexors and hip flexors $(\mathrm{r}=-0.245, \mathrm{P}=0.012)$. Similar correlation was found between BMI and lower-limb extensors ( $\mathrm{r}=-0.237, \mathrm{P}=0.015)$. The strength of the studied muscle groups decreased in parallel to weight gain in children. The comparison of children's BMI with trunk extensors also revealed a negative correlation without statistically significant differences.
The association between preschool age children not engaged in sport and the circumference of the abdomen, abdominal, trunk and gluteal muscle strength was evaluated. No statistically significant differences between mean BMI of children engaged in sport or not were found - 19.7 \pm 2.7 and $19.5 \pm 2.9$, respectively.

There were not considerable differences in mean circumference of the abdomen values of children engaged in sport $(66.5 \pm 6.2 \mathrm{~cm})$ or not $(67.5 \pm 8.4 \mathrm{~cm})$ with higher abdominal circumference in the latter subgroup (Table 3).

Table 3. Anthropometric parameters in physically active and physically inactive children.

\begin{tabular}{|l|l|r|r|r|r|}
\hline Parameters & \multicolumn{1}{|c|}{$\mathrm{N}$} & \multicolumn{1}{c|}{ Mean } & Std. Deviation & \multicolumn{1}{c|}{ Std. Error Mean } \\
\hline $\begin{array}{l}\text { Abdominal } \\
\text { circumference }\end{array}$ & Physically active & 37 & 66,608 & 6,2374 & 1,0254 \\
\cline { 2 - 6 } & Physically inactive & 71 & 67,528 & 8,3529 &, 9913 \\
\hline Abdominal flexors & Physically active & 37 & 14,68 & 8,910 & 1,465 \\
\cline { 2 - 6 } & Physically inactive & 71 & 14,11 & 10,028 & 1,190 \\
\hline \multirow{2}{*}{$\begin{array}{l}\text { Lower-limb } \\
\text { extensors }\end{array}$} & Physically active & 37 & $\mathbf{1 3 , 8 6}$ & 8,587 & 1,412 \\
\cline { 2 - 6 } & Physically inactive & 71 & $\mathbf{1 0 , 2 5}$ & 9,447 & 1,121 \\
\hline Trunk extensors & Physically active & 37 & 30,27 & 19,782 & 3,252 \\
\cline { 2 - 6 } & Physically inactive & 71 & 23,85 & 14,870 & 1,765 \\
\hline BMI & Physically active & 37 & 19,670 & 2,6910 &, 4424 \\
\cline { 2 - 6 } & Physically inactive & 72 & 19,518 & 2,9937 &, 3553 \\
\hline
\end{tabular}

Abdominal flexor test values of physically active children $-14.7 \pm 8.9 \mathrm{~s}$ were not significantly different from those who were physically inactive $-14.1 \pm 10 \mathrm{~s}$. According to the results, the latter had weaker abdominal muscles.

Similar were the findings for trunk extensors $(\mathrm{P}>0.05)$ in physically active and physically inactive children $(30.3 \pm 19.8 \mathrm{~s}$ and $23.9 \pm 14.9 \mathrm{~s}$, respectively). The trunk muscles were weaker in physically inactive children.

However, the average values for lower-limb extensors differed substantially $(\mathrm{P}=0.01)$ in the physically active ones $(13.9 \pm 8.6 \mathrm{~s})$ than in the others $(10.3 \pm 9.4 \mathrm{~s})$. Gluteal muscles were weaker in children that were not involved in any sport activity (Figure 4).

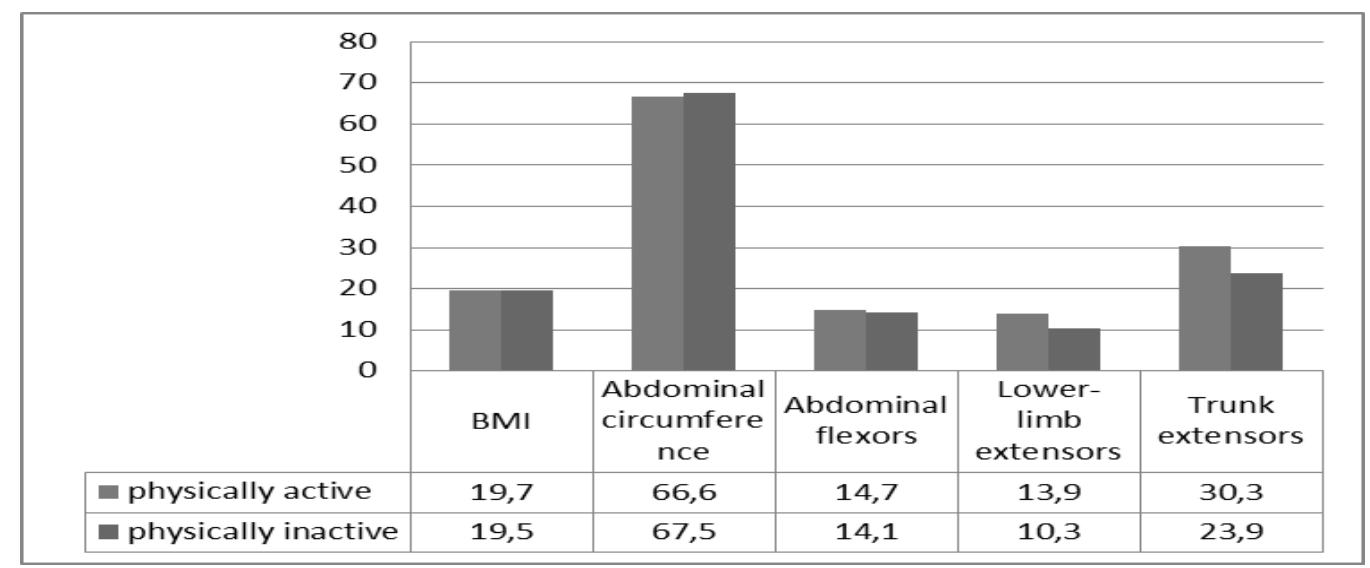

Figure 4. Distribution of average anthropometric parameters in physically active and physically inactive children. 
The lack of correlations between BMI and circumference of the abdomen in preschool age children depending on their involvement in sport could be attributed to the small cohort size, as studies performed globally provide evidence for the role of physical activity both for body weight and abdominal circumference reduction.

No statistically significant differences in abdominal and trunk muscles were found out between physically active and physically inactive children, although abdominal, gluteal and trunk muscles were weaker in physically inactive children, e.g. they showed a lower level of static strength. Literature reviews clearly demonstrated the role of physical activity and sport for weight reduction as well as for improvement of the overall psychophysical development.

\section{CONCLUSIONS}

The results obtained from our study did not reveal statistically significant differences in the strength of the abdominal and trunk muscles between physically active and physically inactive children. Nevertheless, in the studied group we found weaker abdominal, trunk and gluteal muscles and respectively a lower level of static strength endurance in children who do not do sports outside kindergarten. In our opinion, additional studies are needed to establish the relationship between weight gain in children and strength endurance of the abdominal, trunk and gluteal muscles as a factor counteracting overall muscle hypotonia and postural control.

\section{REFERENCES}

1. Traykova, Ts. State of physical development and motor abilities of children in a preparatory group for school (5-7 years old). Author's abstract of a dissertation for awarding the educational and scientific degree "Doctor". NSA V. Levski, Sofia, 2018.

2. Reilly JJ. Physical activity, sedentary behavior and energy balance in the preschool child: opportunities for early obesity prevention. Proc Nutr Soc;67(3):317-25, 2008.

3. http://www.who.int/en/news-room/factsheets/detail/obesity-and-overweight

4. Damyanova, M., Mihailova, E., Mumdzhiev, N., Stanimirova, N., Konstantinova, M. Obesity in childhood.
Ed. of M. Damyanova, S., Med. and Phys., 166 p., 1990.

5. Reilly JJ, Armstrong J, Dorosty AR, Emmett PM, Ness A, Rogers I, Steer C, Sherriff A; Avon Longitudinal Study of Parents and Children Study Team. Early life risk factors for obesity in childhood: cohort study.BMJ.2005 Jun 11;330(7504):1357. Epub May 20, 2005.

6. Alexiev, R. On some aspects and problems of physical activity and health of children in modern kindergartens. Scientific works of the University of Ruse, volume 48, series 8.2- 63-66, 2009.

7. Baeva, M. Pedagogical aspects of motor and health hygiene. S., Preschool education, vol. 5-6, 2000.

8. Goldfield GS, Mallory R, Parker T, Cunningham T, Legg C, Lumb A, Parker K, Prud'homme D ,Gaboury I, Adamo KB Effects of open-loop feedback on physical activity and television viewing in overweight and obese children: a randomized, controlled trial. Pediatrics. Jul;118(1):e157-66, 2006.

9. Filkova, S., Bogomilova, S., Tarpomanova, Ts. Study of the motor activity of children with obesity. Varna Medical Forum, vol. 4, appendix 3, MU-Varna, pp. 393-397, 2015.

10.Pradinuk M., Jean-Pierre Chanoine, Ran D. Goldman, Obesity and physical activity in children, | Canadian Famiiy Physician Le Médecin de famille canadien vol 57: july juillet 2011.

11. Vale S., Santos R., Soares-Miranda L., C. Moreira, J.R.Ruiz, J.Mota. Objectively Measured Physical Activity and Body Mass Index in Preschool Children, Hindawi Publishing Corporation International Journal of Pediatrics Volume, 1-6, 2010.

12.Lateva, M. Adiponectin and some other markers of metabolic risk and their connection with abdominal obesity in preschool children. Abstract of a dissertation for the award of educational and scientific degree "Doctor" Varna, 2015.

13.http://www.cdphe.state.co.us/pp/COPAN/e arlychildhood/BestPracticesBook.pdf

14. Karaneshev, G. Theory and methodology of therapeutic exercise. Textbook for NSA students. Medicine and Physical Education, Sofia, 1991.

15.Marekov, M., G. Karaneshev. Kinesitherapy for internal and nervous diseases. Blagoevgrad, 2000.

16.Paskaleva R., Practical guide to kinesitherapy in socially significant 


\section{PAVLOVA V., et al.}

diseases in childhood, Textbook, Publishing House EX-PRESS - Gabrovo; pp. 146; 2013

17.Paskaleva R. Kinesitherapy in common diseases in childhood and relaxation techniques. Textbook. Publisher: EXPRESS Gabrovo; 227s, 2015.

18.Paskaleva R. Kinesitherapy and art therapy for diseases in childhood. Textbook. Publisher: EX-PRESS Gabrovo; 180 s, 2020.
19. Koleva, I. A short course in kinesitherapy. Sofia, 2009.

20.Koleva, I. Fundamentals of rehabilitation / with algorithms for socially significant diseases and injuries of the nervous system and musculoskeletal system / - Sofia, RIC "SIMEL", 2010.

21.Bogomilova, S., Ivanova, E., YordanovaNestorova, K. Study of the possibilities of kinesitherapy for dealing with obesity in school age. Varna Medical Forum, vol. 5, appendix 3, MU-Varna, pp. 170-173., 2016. 